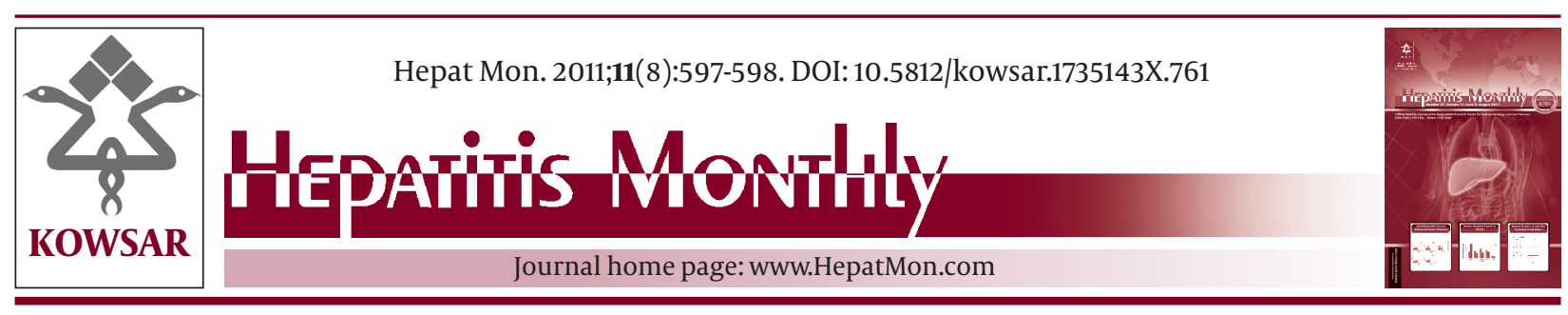

\title{
Hepatitis B Vaccination Reliability in Celiac Disease
}

\author{
Mohammad Rostami Nejad ${ }^{1}{ }^{*}$, Kamran Rostami $^{2}$, Mohammad Reza Zali $^{1}$ \\ ${ }^{1}$ Research Center for Gastroenterology and Liver Disease, Shahid Beheshti University of Medical Sciences, Tehran, Iran \\ 2 Acute Medicine, Dudley Group of Hospital, Dudley, UK
}

A R T I C L E I N F O

Article Type:

Editorial

Article history:

Received: 04 Aug 2011

Revised: 10 Aug 2011

Accepted: 13 Aug 2011

\section{Keywords:}

Hepatitis B virus

Vaccination

Antibody

Vaccination is an efficient and reliable means of protection against common hepatitis B virus (HBV) infections (1). Between $90 \%$ and $95 \%$ of the adult population responds to $\mathrm{HBV}$ vaccination $(2,3)$, and $4-10 \%$ of vaccine recipients fail to respond to standard immunization (1, $4,5)$. The ability to respond to recombinant HBV vaccine is associated with immunogenetically condition because of multiple candidate genes $(6,7)$. Some specific HLA haplotypes are considered to be the most important genetic markers for non-responders, who are found to carry specific haplotypes such as B8, DR3, and DQ2 $(6,7)$. Since HLA genotypes play an important role in unresponsiveness to the HBV vaccine, celiac disease $(\mathrm{CD})$ may be associated with this unresponsiveness (8). CD is a common autoimmune disorder, which has a particularly strong association with the presence of HLA-DQ2 in $90-95 \%$ of the patients (9-12).

In an issue of Hepatitis Monthly (13), Ertekin et al. reported the results of their study on 52 children with $\mathrm{CD}$ and 20 age- and sex-matched healthy children who

${ }^{*}$ Corresponding author at: Mohammad Rostami Nejad. Research Centers for Gastroenterology and Liver Diseases, Shaheed Beheshti University of Medical Sciences, Tehran, IR Iran. Tel: +98-2122432518, Fax: +98-2122432517.

Email:m.rostamii@gmail.com

DOI:10.5812/kowsar.1735143X.761

Copyright $\odot 2011$, BRCGL, Published by Kowsar M.P.Co. All rights reserved.
-Implication for health policy/practice/research/medical education:

Hepatitis B vaccination plays an important role in HBV prevention. Special groups of patients, such as patients with celiac disease respond differently to $\mathrm{HBV}$ vaccination. We highly recommend Gastroenterologists, infectious specialists, pediatricians, immunologists and virologists to study this article.

- Please cite this paper as:

Rostami Nejad M, Rostami k, Zali MR. Hepatitis B Vaccination Reliability Celiac Disease. Hepat Mon. 2011;11(8):597-8. [DOI: 10.5812/kowsar.1735143X.761]

๑ 2011 Kowsar M.P.Co. All rights reserved.

received $\mathrm{HBV}$ vaccination as per an immunization schedule. The proportion of children in the CD group who failed to respond to HBV vaccination (32 of 52) was significantly higher than the proportion of control individuals who did not (18 of $20 ; 61.5 \%$ vs. $90 \%$; $P<$ 0.05). Ertekin et al. concluded that unresponsiveness to hepatitis $\mathrm{B}$ vaccination was found in a higher percentage in children with $C D$ than the control group. They concluded that response to the HBV vaccine in children with CD should be investigated and a different immunization schedule should be developed for them. They also suggested that compliance with a glutenfree diet may improve the immune response of celiac children to the HBV vaccine. Most studies on this topic have demonstrated that the number of children with $C D$ who failed to respond to the HBV vaccine is significantly greater than that of healthy children $(4,5,8,14)$.

In a similar study on an adult cohort, Noh et al. found that of 23 adults with $C D$ who had completed a full course of HBV vaccination, 19 tested positive for HBsAb and 13 did not show long-term immunity (15).

This association of HLA with non-responsiveness to HBV vaccination was further confirmed in a study by Stachowski et al., where 34 out of 153 patients with endstage renal disease were non-responsive to a recombinant HBV vaccine and HLA-DQ2 was found almost exclusively 
in the non-responder group (7).

Longer intervals between vaccination and antibody testing might be one of the reasons for significantly low protective post-vaccination HBV antibody titers even in CD patients who comply with dietary guidelines (8, 14). Therefore, revaccination is recommended when the patients are following a controlled gluten-free diet.

This study was not designed to determine the presence of HLA-DQ2 and HLA-DQ8 in both the groups. Therefore, future studies evaluating the HLA haplotypes in $\mathrm{CD}$ and control groups should aim to characterize the role of HLA typing in the response to HBV vaccination.

As in the case of other conditions and as indicated by the strong evidence for the protective role of GFD, early diagnosis of $C D$ may obviously increase the percentage of patients responding to the HBV vaccine. Moreover, beginning with a short duration, strict, gluten-free diet seems to play a positive role in the development of antibody memory. Given the high prevalence of CD in the general population and a lack of response to HBV vaccine in untreated patients, we think that non-responsiveness to $\mathrm{HBV}$ vaccine necessitates routine assessment in patients with $\mathrm{CD}$. Non-responsiveness to $\mathrm{HBV}$ vaccine may be a possible sign of undiagnosed $C D$ or may suggest noncompliance with gluten-free diet.

\section{References}

1. Ahishali E, Boztas G, Akyuz F, Ibrisim D, Poturoglu S, Pinarbasi B, et al. Response to hepatitis $B$ vaccination in patients with celiac disease. Dig Dis Sci. 2008;53(8):2156-9.

2. Poland GA. Hepatitis B immunization in health care workers.
Dealing with vaccine nonresponse. Am J Prev Med.1998;15(1):73-7.

3. Safary A, Andre F. Over a decade of experience with a yeast recombinant hepatitis B vaccine. Vaccine. 1999;18(1-2):57-67.

4. Nemes É, Lefler É, Szegedi L, Kapitány A, Kovács JB, Balogh M, et al. Gluten intake interferes with the humoral immune response to recombinant hepatitis $B$ vaccine in patients with celiac disease. Pediatrics. 2008;121(6):e1570.

5. Ertem D, Gonen I, Tanidir C, Ugras M, Yildiz A, Pehlivanoglu E, et al. The response to hepatitis B vaccine: does it differ in celiac disease? Eur J Gastroen Hepat. 2010;22(7):787.

6. Martinetti M, De Silvestri A, Belloni C, Pasi A, Tinelli C, Pistorio A, et al. Humoral response to recombinant hepatitis $B$ virus vaccine at birth: role of HLA and beyond. Clin Immunol. 2000;97(3):23440 .

7. Stachowski J, Kramer J, Fust G, Maciejewski J, Baldamus CA Petranyi GG. Relationship between the reactivity to hepatitis B virus vaccination and the frequency of MHC class I, II and III alleles in haemodialysis patients. Scand J Immunol. 1995;42(1):60-5.

8. Park SD, Markowitz J, Pettei M, Weinstein T, Sison CP, Swiss SR, et al. Failure to respond to hepatitis B vaccine in children with celiac disease. J Pediatr Gastroenterol Nutr. 2007;44(4):431-5.

9. Zali MR, Rostami Nejad M, Rostami K, Alavian SM. Liver complications in celiac disease. Hepat Mon. 2011; 11(5): 333-341.

10. Rostami Nejad M, Rostami K, Emami MH, Zali MR, Malekzadeh R. Epidemiology of Celiac Disease in Iran: A Review. Middle East. J Dig Dis. 2011;3(1):5-12.

11. van Heel DA, West J. Recent advances in coeliac disease. Gut. 2006;55(7):1037-46.

12. Kapitány A, Toth L, Tumpek J. Diagnostic significance of HLA DQ typing in patients with previous coeliac disease diagnosis based on histology alone. Aliment Pharm Therap. 2006;24(9):1395-402.

13. Ertekin V, Tosun $M$, Selimoğlu M. Is there need to a new hepatıtıs b vaccine schedule in children with celiac disease? Hepat Mon. 2011:[Epub a head of print].

14. Leonardi S, Spina M, Spicuzza L, Rotolo N, La Rosa M. Hepatitis B vaccination failure in celiac disease: is there a need to reassess current immunization strategies? Vaccine. 2009;27(43):6030-3.

15. Noh KW, Poland GA, Murray JA. Hepatitis B vaccine nonresponse and celiac disease. Am J Gastroenterol. 2003;98(10):2289-92. 